\title{
Filling and Recycling Apparatus of a Cyclotron Target with Enriched Krypton for Production of Radiopharmaceuticals
}

\author{
M. Vognar, M. Fišer, Č. Šimáně, D. Chvátil
}

\begin{abstract}
An apparatus for multiple filling of a cyclotron target with enriched Kr gas is described. The system is based on recycling pressurized gas by cryogenic pumping between the target tube and storage containers. The design and construction makes use of previous experience in the construction and operation of two analogue apparatuses for Xe $e^{124}$ high pressure gas targets, but major modifications have been incorporated, evoked by the different physical properties of $\mathrm{Kr}$, by the character of the nuclear reaction, and by the demand for automation from the side of the end user.
\end{abstract}

Keywords: generator, Kr gas target, ${ }_{36} K^{82}(p, 2 n){ }_{37} R b^{81}$ reaction .

\section{Introduction}

Cyclotron - produced ${ }^{81} \mathrm{Rb}\left(\mathrm{T}_{1 / 2}=4.58 \mathrm{H}\right)$ and its daughter ${ }^{81 \mathrm{~m}} \mathrm{Kr}\left(\mathrm{T}_{1 / 2}=13.3 \mathrm{~s}\right)$ constitute a radionuclide generator for nuclear medicine used as a common tool for lung ventilation studies. The main advantages of this generator are the good imaging properties of ${ }^{81 \mathrm{~m}} \mathrm{Kr}$ and the low radiation dose in tissue. Because demand for such a system exists, it was decided to develop an appropriate target and radiopharmaceutical assemblies. These considerations led to a project to make an apparatus for producing radionuclide ${ }_{37} \mathrm{Rb}^{81}$.

The authors have experience in constructing and operating of filling and recycling apparatus for production of ${ }^{123} \mathrm{I}$ on electron accelerators [1], [2] for gaseous Xe targets (natural xenon and xenon enriched by ${ }^{124} \mathrm{Xe}$ ). The distinctive character of these apparatuses is the irradiation of gaseous targets in the proximity of the critical point of Xe to guarantee high effectiveness and reproducible yield of ${ }^{123} \mathrm{I}$ from $(\gamma, \mathrm{n})$ reaction during irradiation of ${ }^{124} \mathrm{Xe}$.

By contrast, cyclotron targets work at lower pressure, resulting from the reaction conditions of protons with the target material, i.e., from the „square density” parameter and necessary loss of energy for a given reaction channel, e.g.,

$$
{ }_{36}^{82} K r(p, 2 n)_{37}^{81} R b \frac{T_{1 / 2}=4.58 h}{E C(67 \%), \beta^{+}(27 \%)}{ }^{81 m} K r \quad c \quad \begin{gathered}
T_{1 / 2}=13.3 h \\
E C, E_{\gamma}=190.3 k e V(67 \%) .
\end{gathered}
$$

For a thick target and proton energy EP $=(29 \rightarrow 23) \mathrm{MeV}$ the yield is about $48 \mathrm{mCi} /(\mu \mathrm{A} \cdot \mathrm{h})$.

When working with expensive krypton, highly enriched in one of its isotopes, it is necessary to ensure multiple recycling without significant losses and pollution of the gas.

The recycling of the gas in the apparatus is achieved by cryogenic pumping at the temperature of liquid nitrogen. Before the gas transfer, the transport volume of the apparatus must be evacuated to about $10^{-2} \mathrm{~Pa}$. The pressure of gas vapors at liquid nitrogen temperature for $\mathrm{Kr}$ is $133 \mathrm{~Pa}$, which is three orders of magnitude higher than for Xe $(0.1 \mathrm{~Pa})$. To reduce the losses of $\mathrm{Kr}$ gas per one pumping cycle, the vapor pressure must be reduced by using a suitable solid adsorbent within the pumped volume.
A diagram of the apparatus is schematically shown in Fig. 1. For completeness, the radiochemical, drying and target tube subsystems, which were made in the NPI of CAS, are indicated in gray. Fig. 2 illustrates the apparatus in development.

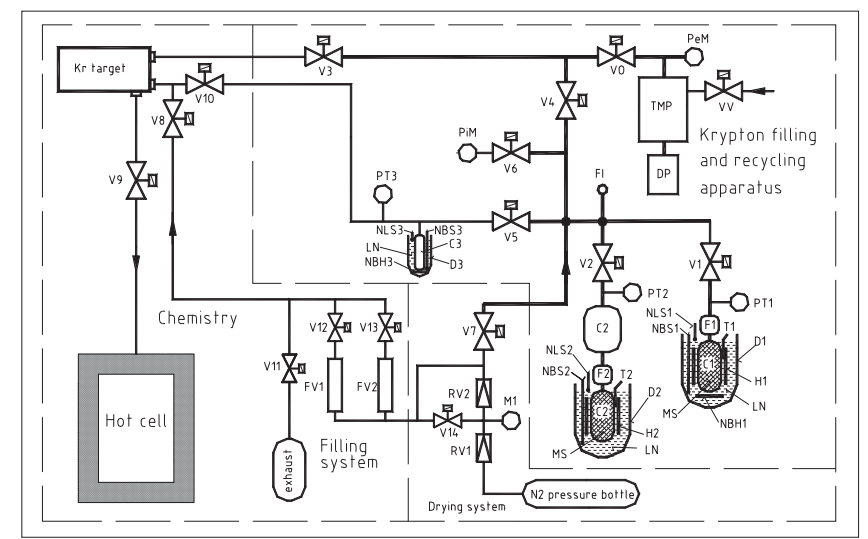

Fig. 1: Scheme of the filling and recycling apparatus:

DP - diaphragm vacuum pump, TMP - turbomolecular vacuum pump, C1 - working container, C2 - storage container, MS - molecular sieve, C3 - intermediate high pressure container (Kr trap), D1 to D3 - Dewar flasks, LN - liquid nitrogen, F - microfilter, V1 to V13 - valves, RV1, RV2 - pressure reduction valves, VV - venting valve, FI - first filling inlet fitting, $\mathrm{H} 1$ and $\mathrm{H} 2$ - container thermocoax heating elements, PiM - Pirani vacuum gauge, PeM - Penning vacuum gauge, PT1 to PT3 - pressure transducers, M1 - manometer, T1, T2 -thermocoax thermocouples for measuring of the gas temperature, NLS1 to NLS3 - liquid nitrogen level sensors, NBS1 and NBS3 - sensors for control nitrogen boiling, NBH1 and NBH3 - heaters for boiling out liquid nitrogen, FV1, FV2 - filling volumes

Fig. 1 shows the apparatus together with the radiochemical, drying and target tube subsystems, made in the NPI of CAS.

The scheme is much more complicated than the apparatus in [1] and [3]. This is due partly to the need to use molecular sieves, partly to satisfy the requirement that it should be possible to automate the process with the use of a PC and RS 232 interface. 


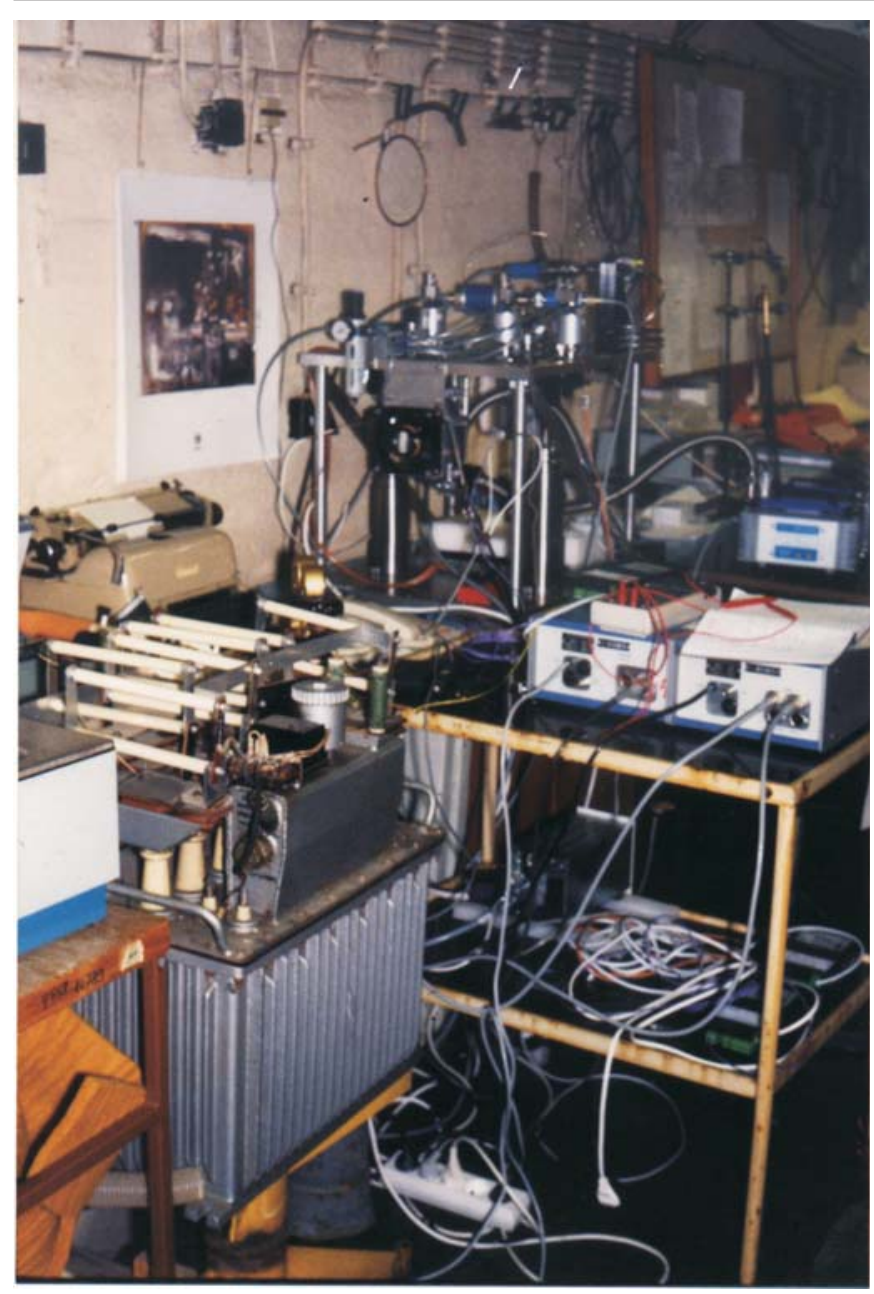

Fig. 2: Overall view of the filling and recycling apparatus at the development stage

\section{Description of the apparatus}

The pumping system consists of a diaphragm vacuum pump DP and a turbomolecular pump TMP, which can be separated from the rest of the apparatus by the valve V0. To prevent the transfer of mechanical vibrations from the diaphragm pump to the turbomolecular pump, the former is suspended on spiral springs on a separate stand and connected with the turbomolecular pump, mounted on the main stand, by a bellow hose provided with additional damping.

The complete filling and recycling apparatus consists of working pressure container C1, storage container C2, high pressure intermediate container C3 (Kr trap), high pressure and vacuum tight, pneumatically actuated high pressure bellow valves V0 to V6, an electrically controlled pressure air distribution system to the valves, pressure transducers PT1 to PT3, and Penning type PeM and Pirani type PiM vacuum gauges. The system is mounted together with the corresponding armatures and tubing on the supporting plate on the main stand. The apparatus is accessible for the first filling by the fitting F1, which is permanently all time blinded during operation. For the connection with the target, the other end of the apparatus is provided with a tube coupling of Ultraseal type for evacuation and with two Swagelock couplings for filling the target from the intermediate container and for chemical treatment of the product.

The stainless steel Dewar flasks for freezing the gas in containers C1 and C2 are mounted on an auxiliary plate on the main stand. The Dewar flask D3 for freezing the gas in the intermediate container C3 is suspended on the main supporting plate.

The thermocouples NLS1 to NLS3, for sensing the liquid nitrogen level in the Dewar flask during automatic filling and refilling, are fixed on Dewar flasks D1 to D3 as well as the thermocouples NBS1 and NBS3 for control of boiling out the nitrogen in Dewar flasks D1 and D3.

Containers $\mathrm{C} 1$ and $\mathrm{C} 2$ are provided with thermocoax heating elements $\mathrm{H} 1$ and $\mathrm{H} 2$ wound in spiral grooves on the outer surfaces. The resistance of the heating elements is approx. $6 \mathrm{ohms}$, and the heating power is $150 \mathrm{~W}$. The surface temperature of the containers is measured by thermocoax thermocouples $\mathrm{T} 1$ and $\mathrm{T} 2$, wound along the heating elements in several grooves and connected to two-level comparators. The working temperature is stabilized at $320{ }^{\circ} \mathrm{C}$. In the event of accidental overheating the comparators automatically switch off the heaters at $350^{\circ} \mathrm{C}$. Restarting must be done manually.

The pressure of the gas in the containers during heating and transfer is controlled by pressure transducers PT1 to PT3, which are high vacuum tight and work up to $20 \mathrm{MPa}$. Pressure transducer PT3 indicates the pressure of the gas in the target, when valves $\mathrm{V} 5$ and $\mathrm{V} 3$ are closed.

Heating elements NBH1 to NBH3 (4 ohm resistor wire), for quick removal of liquid nitrogen by boiling it out, are installed on the bottom in Dewar flasks D1 and D3. The heating power in the presence of liquid nitrogen in the flask is $145 \mathrm{~W}$. When the nitrogen has been boiled out and the temperature, as measured by thermocouples NBS1 and NBS3, reaches $0{ }^{\circ} \mathrm{C}$ the power is automatically reduced to $35 \mathrm{~W}$. At this heating power the temperature is stabilized at about $80^{\circ} \mathrm{C}$. The switching and stabilization is accomplished by two level thermostats. At the beginning, when heating starts, low power heating is set automatically. High power heating is switched on by a starting impulse, activated only if there is liquid nitrogen in the Dewar flask.

The Penning type PeM vacuum gauge indicates the high vacuum level in the tubing between the turbomolecular pump and valve V0. The Pirani vacuum gauge for indicating pressure from $10^{-1}$ to $10^{3} \mathrm{~Pa}$ can be separated from the rest of the apparatus by valve V6, which must be closed before the pressure in the connecting tubing rises above 0.1 MPa, otherwise its vacuum tightness will be lost.

The complete production system consisting of the target, the filling and recycling apparatus, together with auxiliary parts, is mounted on a mobile carriage. For irradiation, the carriage is moved to the proton beamline. All the electronic blocks are kept at a sufficient distance from the beam to prevent radiation damage.

\section{Target construction}

The scheme of the target system is sketched in Fig. 3; the assembly of the target is shown in Fig. 4. All parts of the sys-

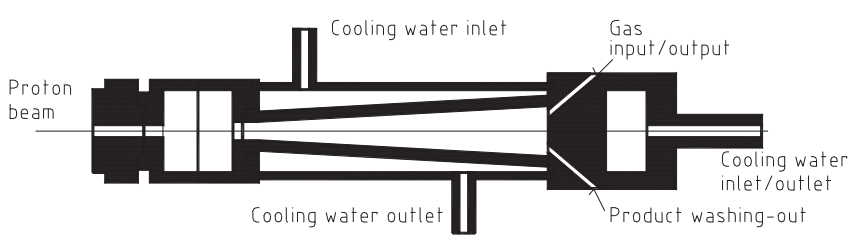

Fig. 3: Schematic drawing of the Kr target 


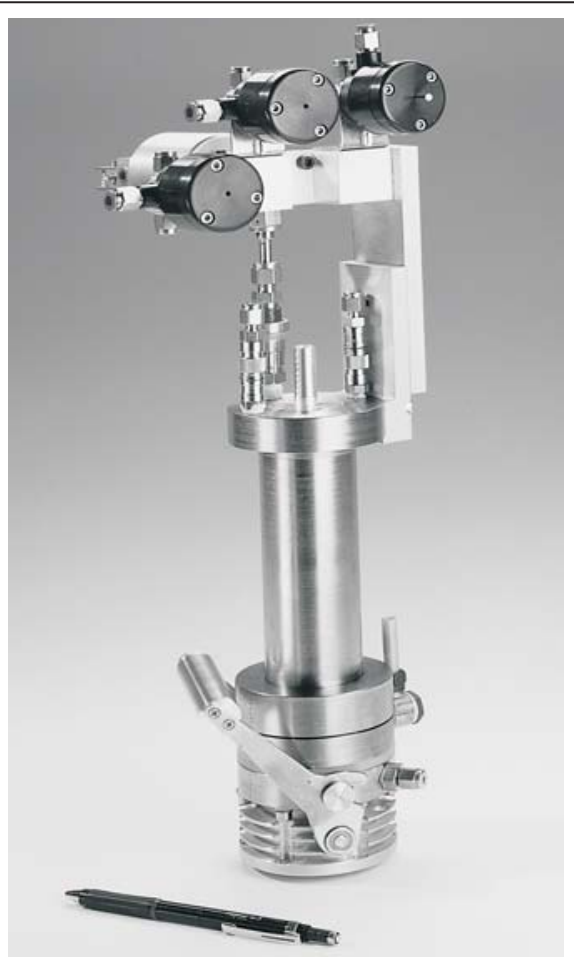

Fig. 4: Photograph of the pressure gas target

tem are made of material that is only to a small extent activated by scattered particles of the beam. A thin compact Ni layer coats the interior of the tube, the entrance window of the target is made of Ti foil, and the material of the scatter foil is pure Al. A beam stopper is integrated at the tube outlet, which, like the surfaces of the other parts, is cooled by water. The target system is electrically insulated from the output accelerator flange.

The target is operated at a pressure of 1-2 MPa, with proton beam energy $\mathrm{E}_{\mathrm{p}}=28 \mathrm{MeV}$ and energy loss of 6-7 MeV in the target gas.

\section{Operating procedure}

The molecular sieves in the storage (working) containers $\mathrm{C} 2$ (C1) are activated by heating them to $320^{\circ} \mathrm{C}$ under continuous pumping by the turbomolecular pump TMP and the diaphragm vacuum pump DP. If the nominal vacuum is reached, valve V2 (V1) is closed. Then the apparatus is evacuated to $10^{-2} \mathrm{~Pa}$.

The gas from the transport flask $\left(625 \mathrm{~cm}^{3}\right.$ at $\left.1 \mathrm{bar}, 20{ }^{\circ} \mathrm{C}\right)$ is attached to the first filling fitting F1. The apparatus, including the fitting armature, is evacuated and when the pressure descends to $10^{-2} \mathrm{~Pa}$, and all valves are closed. The Dewar flask of the working container C1 is filled with liquid nitrogen and the valves of the transport flask and valve $\mathrm{V} 1$ of the working container C1 are opened. When the pressure, indicated on PT1, descends to negative values, valve V6 is opened, and the pressure is measured by the Pirani gauge. At a pressure below $0.5 \mathrm{~Pa}$ the valve $\mathrm{V} 1$ and the valve of the transport flask are closed, as is V6. The transport flask is removed and filling fitting F1 is blinded. By opening valves V0 and V4, the aerated volume is evacuated again to $10^{-2} \mathrm{~Pa}$, and after valves $\mathrm{V} 0$ and $\mathrm{V} 4$ have been closed the apparatus is ready for the first cycle, i.e., for the transfer of the gas in the target.

For this purpose, the Dewar flask of the intermediate container ( $\mathrm{Kr}$ trap) $\mathrm{C} 3$ is filled with liquid nitrogen and container $\mathrm{C} 1$ is heated by thermocoax heating element $\mathrm{H} 1$ to
$320{ }^{\circ} \mathrm{C}$. If there is liquid nitrogen present in container $\mathrm{C} 1$, heater NBH1 is switched on and liquid nitrogen is boiled out. After that, valves V1 and V2 will be opened and the gas from C1 will freeze in container C3. At pressure lower than $0.1 \mathrm{MPa}$, valve V6 is opened and further decrease of the pressure is measured by the Pirani gauge. When the pressure decreases below $150 \mathrm{~Pa}$, valve V5 is closed. In following steps the heating of $\mathrm{C} 1$ is switched off, $\mathrm{D} 1$ is filled with liquid nitrogen and the rest of the gas between valves V2, V4, V5 and the blinded filling fitting is transferred by cryogenic pumping to C1. Valve $\mathrm{V} 1$ is closed when the pressure descends below $0.5 \mathrm{~Pa}$. After that, heater NBH3 in C3 is switched on and the liquid nitrogen boiled out. The pressure in the target, measured by pressure transducer PT3, rises to approximately $2 \mathrm{MPa}$ and from this moment the target is ready for irradiation by protons from the cyclotron. After the end of the irradiation the gas is transferred by cryogenic pumping back either to working container C1 or to storing container $\mathrm{C} 2$, the volume of which is larger than the volume of C1, and the danger of escape of the gas during long-term storage is minimized.

Then the radioisotope deposited on the walls of the irradiation container is eluted for subsequent radiochemical preparation of the end product. The details are explained in [4]. After elution, the apparatus must be dried out, evacuated to working vacuum and prepared for the next recycling.

\section{Approximate duration of individual process cycles}

1. Nominal working vacuum is attained in about 50 to 90 minutes from the start of the TM, depending on the duration for which the apparatus has been held under atmospheric pressure.

2. Heating container $\mathrm{C} 1$ (C2) to $320^{\circ} \mathrm{C}$ and stabilizing the gas pressure at $1.52 \mathrm{MPa}(0.073 \mathrm{MPa})$ takes about 32 minutes.

3. After opening valves V1 and V5, when gas transfer starts from container C1, pressure stabilization (measured by PT3) at $0.64 \mathrm{MPa}$ is attained in about 2 minutes.

4. Freezing out the gas in trap C3 takes about 10 minutes.

5. Heating trap C3 and transferring the gas to the target till the pressure attains $2.17 \mathrm{MPa}$ and the target is ready for irradiation takes about 32 minutes.

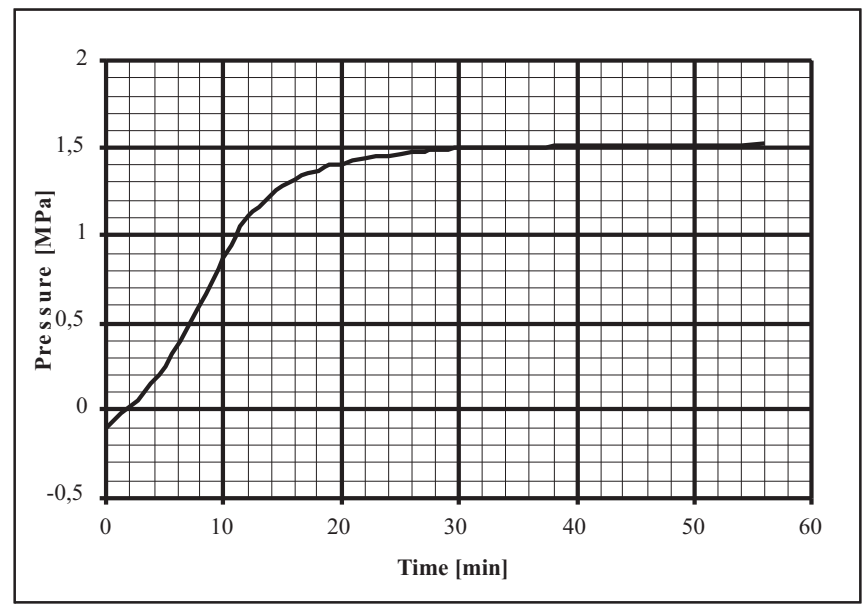

Fig. 5: Pressure of the gas in container $\mathrm{C} 1$ as a function of time elapsed from the beginning of heating from $20{ }^{\circ} \mathrm{C}$ to $320{ }^{\circ} \mathrm{C}$ with $135 \mathrm{~W}$ heating power. The temperature is stabilized at $320^{\circ} \mathrm{C}$; valve V1 remains closed during heating 
6. Recuperation of the gas in the tubing and in the dead volumes of the valves, by freezing it in C1, after the target has been filled and separated from the rest of the apparatus, lasts about 20 minutes.

7. Back transfer of the gas from the target by freezing it in working container C1 lasts about 15 minutes.

The pressure increase in container $\mathrm{C} 1$, containing $628 \mathrm{~cm}^{3}$ $\left(20{ }^{\circ} \mathrm{C} ; 0.1 \mathrm{MPa}\right)$ during heating from room temperature to $320^{\circ} \mathrm{C}$ and from $-193{ }^{\circ} \mathrm{C}$ to $320^{\circ} \mathrm{C}$ (including evaporation of liquid nitrogen) is plotted in Fig. 5 and Fig. 6.

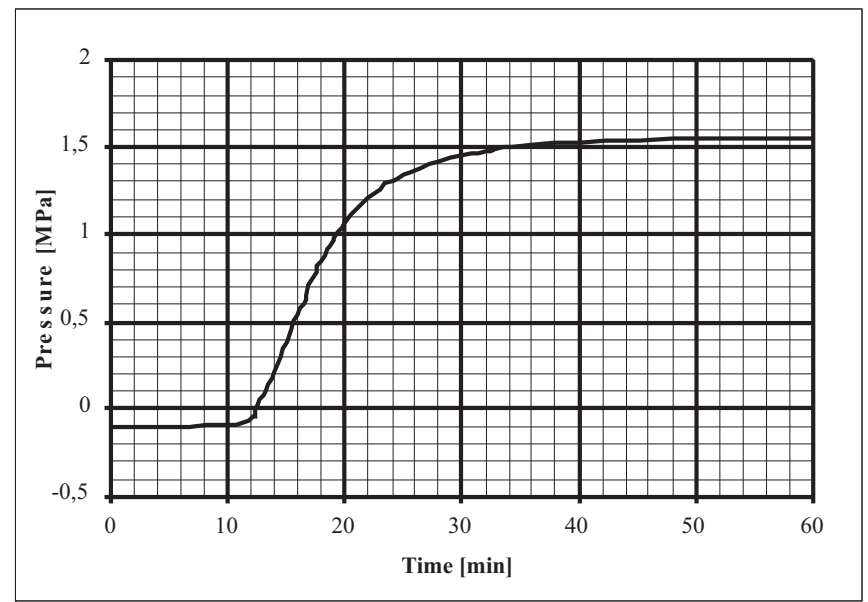

Fig. 6: Pressure of the gas in container $\mathrm{Cl} 1$ as a function of time from the beginning of heating from $-193{ }^{\circ} \mathrm{C}$ to $320^{\circ} \mathrm{C}$. The beginning of the curve corresponds to the boiling out of liquid nitrogen from the Dewar flask with heating power $270 \mathrm{~W}$. When the temperature rises above zero, the power is reduced to $165 \mathrm{~W}$. The temperature is stabilized at $320^{\circ} \mathrm{C}$. During heating valve V1 remains closed.

\section{Main technical parameters}

- Diaphragm vacuum pump 2MD4, Alcatel, pumping speed $3.3 \mathrm{~m}^{3} / \mathrm{h}$, ultimate pressure $200 \mathrm{~Pa}$.

- Turbomolecular vacuum pump ATH 20/40, Alcatel, pumping speed 25/45/1/s, ultimate pressure $<10^{-8} \mathrm{~Pa}$ (when in tandem with diaphragm vacuum pump).

- Container $\mathrm{Cl}$ - volume $60 \mathrm{~cm}^{3}$ including tubing and the dead volume of valve $\mathrm{V} 1$ and filter $\mathrm{F}$, maximum pressure $2 \mathrm{MPa}$, filled in the cooled and heated region with $38.2 \mathrm{~g}$ of Merck zeolite, type $5 \mathrm{~A}$, provided with filters (glass wool, stainless sieve, sintered stainless filter $50 \mu \mathrm{m}$ ) against escape of zeolite powder, range of temperature -195 to $350{ }^{\circ} \mathrm{C}$.

- Container C2 - volume $463 \mathrm{~cm}^{3}$ including tubing and the dead volume of valve V2 and filter $\mathrm{F}, 60 \mathrm{~cm}^{3}$ of which belongs to the cooled and heated section, maximum pressure $2 \mathrm{MPa}$, filled in the cooled and heated region with $39 \mathrm{~g}$ of Merck zeolite, type 5A, provided with filters (glass wool, stainless sieve, sintered stainless filter $50 \mu \mathrm{m}$ ) against escape of zeolite powder, range of temperature of the heated section -195 to $350{ }^{\circ} \mathrm{C}$.

- Container C3 (Kr trap) - volume about $1.5 \mathrm{~cm}^{3}$, maximum pressure $20 \mathrm{MPa}$.

- Valves V0 to V6 pneumatically actuated high-pressure bellows valves, pressure max. $24 \mathrm{MPa}$, vacuum tight.

- Tubing - stainless steel, OD from $1 / 16$ " to $3 / 8$ ", maximum pressure $20 \mathrm{MPa}$, silver brazed, removable vacuum tight joints.
- Target - volume approx. $30 \mathrm{~cm}^{3}$ including dead volumes of tubing and adjacent valves.

\section{Conclusion}

Since the end of 2000, the apparatus has been in use for production of $\mathrm{Rb}^{81} / \mathrm{Kr}^{81 \mathrm{~m}}$ by irradiation of krypton in gas form enriched to $99 \%$ by ${ }_{36} \mathrm{Kr}^{82}$.

Our experience, confirmed in long-term experiments with natural krypton, has shown that the filling and recycling apparatus can guarantee up to 500 cycles without significant loss or pollution of the gas, if the operation instructions are strictly observed. This is very important, when the filling gas is nearly monoisotopic ${ }_{36} \mathrm{Kr}^{82}$, which is expensive $\left(\$ 20 / \mathrm{cm}^{3}\right)$. The apparatus can also be used for production of radioisotopes by other nuclear reactions, for example ${ }_{37} \mathrm{Rb}^{82 \mathrm{~m}}$ in the $(\mathrm{p}, \mathrm{n})$ reaction on ${ }_{36} \mathrm{Kr}^{82}$ on krypton with $90 \%$ content of this isotope.

\section{Acknowledgement}

The authors would like to record their gratitude to Mr. J. Kř́žz and Mr. V. Němec from the Department of Dosimetry and Application of Ionizing Radiation for their valuable collaboration and assistance in constructing the apparatus and in solving some technical problems during production of the mechanical and electronic sections of the apparatus.

\section{References}

[1] Vognar, M., Šimáně, Č.: Laboratory Apparatus for Preparation ${ }^{123}$ I from ${ }^{124} \mathrm{Xe}$ by Photonuclear Reaction.

Acta Polytechnica, Vol. 36, No. 5/1996, pp. 49-56

[2] Vognar, M., Šimáně, Č., Chvátil, D.: Recyklační aparatura pro prípravu ${ }^{123}$ I fotojadernou reakci na ${ }^{124} \mathrm{X}$ e. Závěrečná zpráva k SO č. 403396, KDAIZ FJFI, Praha, 1997

[3] Groszowski, J.: Technika vysokého vakua. SNTL Praha, 1981

[4] Fišer, M., Hanč, P., Lebeda, O., Hradílek, P., Kopička, K.: Development and production of ${ }^{81} \mathrm{Rb} /{ }^{81 \mathrm{~m}} \mathrm{Kr}$ radionuclide generator in NPI. Czech J. Phys. 49 (1999), Suppl. S1, pp. $811-816$

Ing. Miroslav Fišer

Dept. of Radiopharmaceuticals

e-mail: fiser@ujf.cas.cz

Nuclear Physics Institute of CAS

25068 Řež

Ing. Miroslav Vognar

Prof. Ing. Čestmír Šimáně, DrSc.

Ing. David Chvátil

Dept. of Dosimetry \& Appl. of Ionizing Radiation

phone: +4202 2323657, +42022315212

fax: +42022320861

e-mail:Vognar@br.fjfi.cvut.cz

Czech Technical University in Prague

Faculty of Nucleus Sciences and Physical Engineering Břehová 7, 11519 Praha 1, Czech Republic 